\title{
Indications for Protracted Groundwater Depletion after Drought over the Central Valley of California*,+
}

\author{
S.-Y. SIMON WANG \\ Department of Plants, Soils and Climate, and Utah Climate Center, Utah State University, Logan, Utah \\ YEN-HENG LIN \\ Utah Climate Center, Utah State University, Logan, Utah \\ ROBERT R. GILLIES \\ Department of Plants, Soils and Climate, and Utah Climate Center, Utah State University, Logan, Utah \\ KIRSTI HAKALA ${ }^{\#}$ \\ National Research Program, U.S. Geological Survey, Lakewood, Colorado
}

(Manuscript received 1 July 2015, in final form 14 October 2015)

\begin{abstract}
Ongoing (2014-16) drought in the state of California has played a major role in the depletion of groundwater. Within California's Central Valley, home to one of the world's most productive agricultural regions, drought and increased groundwater depletion occurs almost hand in hand, but this relationship appears to have changed over the last decade. Data derived from 497 wells have revealed a continued depletion of groundwater lasting a full year after drought, a phenomenon that was not observed in earlier records before the twenty-first century. Possible causes include 1) lengthening of drought associated with amplification in the 4-6-yr drought and El Niño frequency since the late 1990s and 2) intensification of drought and increased pumping that enhances depletion. Altogether, the implication is that current groundwater storage in the Central Valley will likely continue to diminish even further in 2016, regardless of the drought status.
\end{abstract}

\section{Introduction}

California's Central Valley is undergoing a groundwater drilling boom amid one of the most severe droughts in state history, and new wells often have to be drilled deeper in order to tap into the shrinking aquifer

\footnotetext{
* Utah Agricultural Experiment Station Publication Number 8720 .

${ }^{+}$Supplemental information related to this paper is available at the Journals Online website: http://dx.doi.org/10.1175/ JHM-D-15-0105.s1.

\# Current affiliation: Department of Geography, University of Zurich, Zurich, Switzerland.
}

Corresponding author address: S.-Y. Simon Wang, Department of Plants, Soils and Climate, Utah State University, 4820 Old Main Hill, Logan, UT 84322.

E-mail: simon.wang@usu.edu
(Howard 2014; Kennedy 2014). Drought conditions have forced the state of California to consider new methods and regulations regarding the monitoring and appropriation of groundwater resources (AghaKouchak et al. 2014b). Satellite monitoring of the Gravity Recovery and Climate Experiment (GRACE) has indicated a $31 \pm 3 \mathrm{~km}^{3}$ loss in groundwater storage from 2006 to 2012 (Famiglietti et al. 2011; Scanlon et al. 2012). A recent study (Howitt et al. 2014) estimated that the 2014 drought resulted in an additional groundwater loss on the order of $6.3 \mathrm{~km}^{3}$, and the depletion continues despite efforts to curb water use (Famiglietti 2014).

The present groundwater status in California's Central Valley is rooted in its history. For more than 50 years the Central Valley has been one of the most productive agricultural regions of the world, which is facilitated by sufficient supply of irrigation water (Bertoldi et al. 1991; Faunt 2009). Irrigation and agricultural activity have 
accounted for the vast majority of all water use: during the 1960s and 1970s, annual irrigation water was derived equally from groundwater and surface water, though in drought years the amount supplied by groundwater would increase (Bertoldi et al. 1991). In the early 1980 s, the overall usage of irrigation water increased slightly, and an increased proportion came from surface water. According to USGS water use data for California, from the 1980s until 2010, the Central Valley began using less total water for irrigation, yet there has been an increase in the proportion taken from groundwater sources. The Central Valley has seen a rapid population growth from 5.7 million people in 2000 to 6.7 million people in 2010 (http://www.census. gov/2010census/), leading to increased household usage of water in addition to agricultural water use. In the meantime, groundwater storage in the Central Valley has declined by almost 60 million acre feet since the $1960 \mathrm{~s}$ (Faunt 2009).

Climatic factors have affected groundwater in the Central Valley as well. The effects of global warming at the regional scale include a hotter and drier climate (Dai 2013) and earlier snowmelt (Westerling et al. 2006), both of which can aggravate drought conditions. A companion study that analyzed water cycle extremes in California (Yoon et al. 2015a,b) has projected that both intense drought and excessive flooding will increase by at least $50 \%$ toward the end of the twenty-first century, and such an increase is linked to strengthened impacts from the life cycle of El Niño-Southern Oscillation (ENSO) (Wang et al. 2015). Given the severe drought conditions in California, a pressing question posed is whether the state will experience continued shortfalls in groundwater in upcoming years. To better assess future water resources, this study investigated the linkage between groundwater and drought, and particularly the hypothesis that the recent and projected amplification of water cycle extremes in California (Yoon et al. 2015b) may exacerbate groundwater depletion. Using diagnostic approaches, this study represents a preliminary investigation of likely climatic factors in the drought-groundwater relationship.

\section{Data and methods}

\section{a. Data}

Depicting drought in the state of California can be complicated owing to its terrain and associated snow hydrology. The Palmer drought severity index (PDSI; Dai 2013) has been the most widely used metric for drought depiction and is the front-page indication of drought status in the U.S. Drought Portal (www.drought. gov). Here, we utilized the PDSI data produced by the
Parameter-Elevation Regressions on Independent Slopes Model (PRISM) with a 4-km resolution (http://prism. nacse.org/). However, the PDSI could be problematic in the western United States in that it does not account for time lags introduced by snow accumulation and, as a result, may handle California's snow cycle poorly. Thus, we adopted additional measures of drought by using the Climate Prediction Center (CPC) model-calculated monthly soil moisture water height equivalents (hereafter soil moisture) at $0.5^{\circ}$ grid spacing (http://www.esrl.noaa. gov/psd/data/gridded/data.cpcsoil.html) and the Climatic Research Unit (CRU) Time-Series, version 3.21 (TS3.21), gridded precipitation and temperature data (http://www. cru.uea.ac.uk/data). All these gridded data were averaged in the Central Valley, defined as elevations lower than $1000 \mathrm{~m}$ (Fig. 1a).

For the estimation of groundwater storage, we utilized the level-3 GRACE data of monthly liquid water equivalent thickness (LWET) provided by NASA GRACE Tellus (http://grace.jpl.nasa.gov/; Landerer and Swenson 2012). The GRACE twin satellites detect gravity changes and use them to measure variations in water stored at all levels above and within the land surface; this measurement indicates terrestrial water storage change. The GRACE-derived LWET (hereafter LWET) was averaged within the Central Valley. Although the Central Valley has a smaller areal extent than the GRACE footprint, previous studies (Famiglietti et al. 2011; Scanlon et al. 2012; Anderson et al. 2015) have shown that GRACE-derived groundwater storage change is in agreement with the well data within the valley. We note that the LWET signal may not completely reflect groundwater since the signal leakage effect coming from proximity of the Sierra Mountains (i.e., snow, soil moisture, and surface water) was not removed.

Groundwater level measured by wells within the Central Valley was obtained from two sources: the U.S. Geological Survey (USGS; http://waterdata.usgs.gov/ nwis) and the California Department of Water Resources (DWR; http://www.water.ca.gov/). We used 467 wells as indicated in Fig. 1a; these are wells that provide observations in any month during the SeptemberDecember period with at least 15 years of data. The available data length of each well is plotted as horizontal lines in Fig. S1 of the supplemental material, and the numerous data gaps reflect the well-known problem that groundwater observations in the Central Valley are inhomogeneous and discontinuous (Kennedy 2014). To form long-term time series of groundwater level, one needs to combine these well data; to do so, groundwater level of each well was first standardized (within \pm 1 ) and then averaged across all wells to form a single time series. This procedure eliminates the difference and 


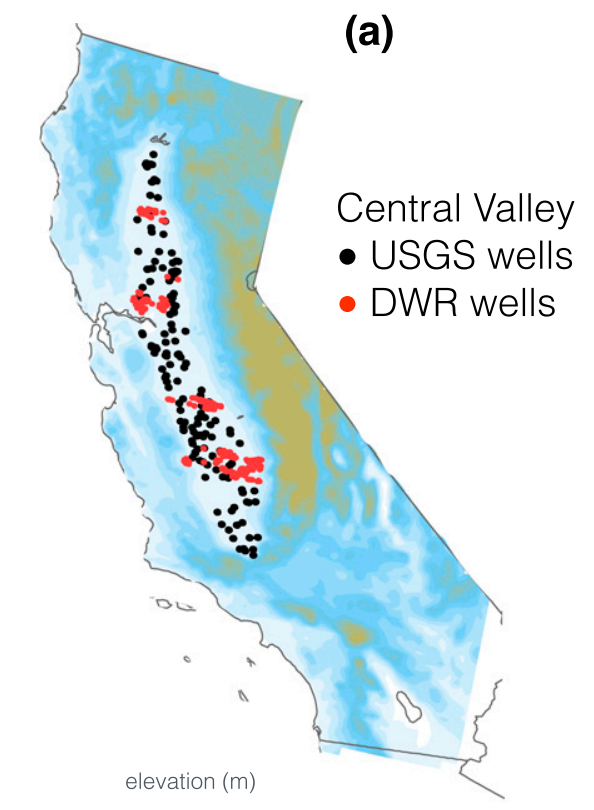

$225 \quad 450 \quad 675 \quad 900 \quad 112513501575180020252250$ (b)

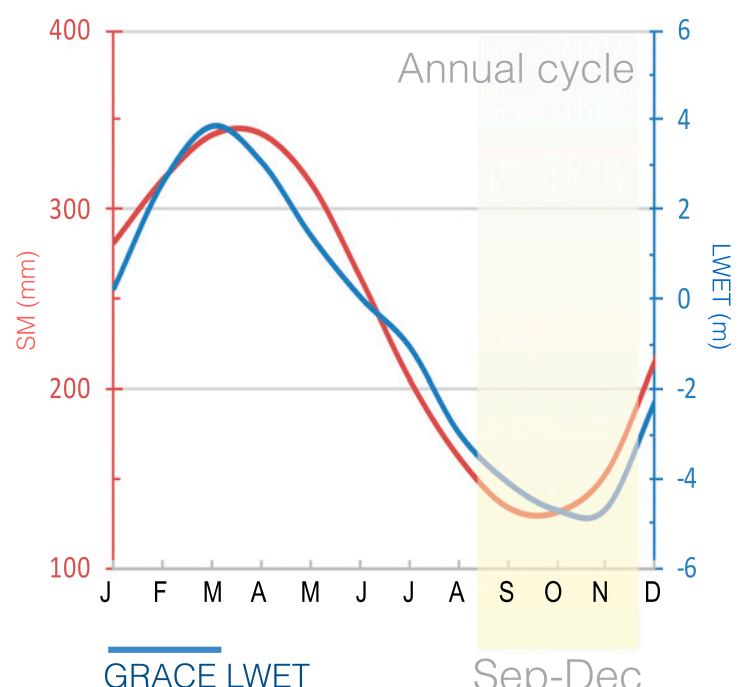

Soil Moisture

FIG. 1. (a) Topography of California that outlines the Central Valley $(<300 \mathrm{~m})$ overlaid with the 497 wells analyzed, obtained from USGS (black dots) and California DWR (red dots). (b) Long-term monthly distribution of LWET (blue) and soil moisture (red) averaged in the Central Valley, while the low season of SeptemberDecember is highlighted.

locality of well levels. As shown in Fig. S1, we conducted a sensitivity test for different parts of the Central Valley: north, central, and south (discussed later). Groundwater level fluctuation is considered uniform throughout the valley despite the limited number of wells after the year 2000. Additional water use data referred to in the text were provided by the USGS (http://waterdata.usgs.gov/ ca/nwis/water_use/).

\section{b. Methods}

To understand the cause and effect of the Central Valley's groundwater problem and to help visualize the temporal change and areal extent from which the problem is derived, we first used the Pearson correlation and cross correlation. Correlation is a simple and direct way to understand the relationship between two variables and associated change, while cross (lagged) correlation provides an effective measure to establish the similarity of two variables as a function of the time lag of one relative to the other. For the purpose of examining the time-frequency distribution of drought and groundwater, that is, how the variation changes over time, as well as further validation of correlation analysis, we conducted the wavelet power spectrum analysis following the derivation of Torrence and Compo (1998). The wavelet coefficients yield information about the correlation between the wavelet (spectral power) and the data array (at a particular data point). To verify lagged correlations, we utilized the wavelet transform coherence (WTC) for analyzing the coherence and phase lag between two time series as a function of both time and frequency. The WTC analysis is based on the continuous wavelet transform developed by Grinsted et al. (2004) for geophysical time series. Significance test was performed by using the Monte Carlo method (i.e., adding random noise to the two signals and repeating this 1000 times) to calculate the $95 \%$ confidence interval about the "true" phase difference.

\section{Results}

In the California Central Valley, groundwater undergoes a pronounced annual cycle that peaks in March and reaches minimum in November, as is displayed in Fig. $1 b$ by the long-term LWET data. Recharge begins in November, at the start of the rainy season, and typically lasts until March. Soil moisture in the Central Valley exhibits an annual cycle similar to LWET (Fig. 1b). Based upon this annual cycle, the period of September-December appears to be the low season of groundwater level. Thus, we divided the year into three different seasons (January-April, May-August, and September-December) and computed the cross correlations between the PDSI and LWET averaged over the 

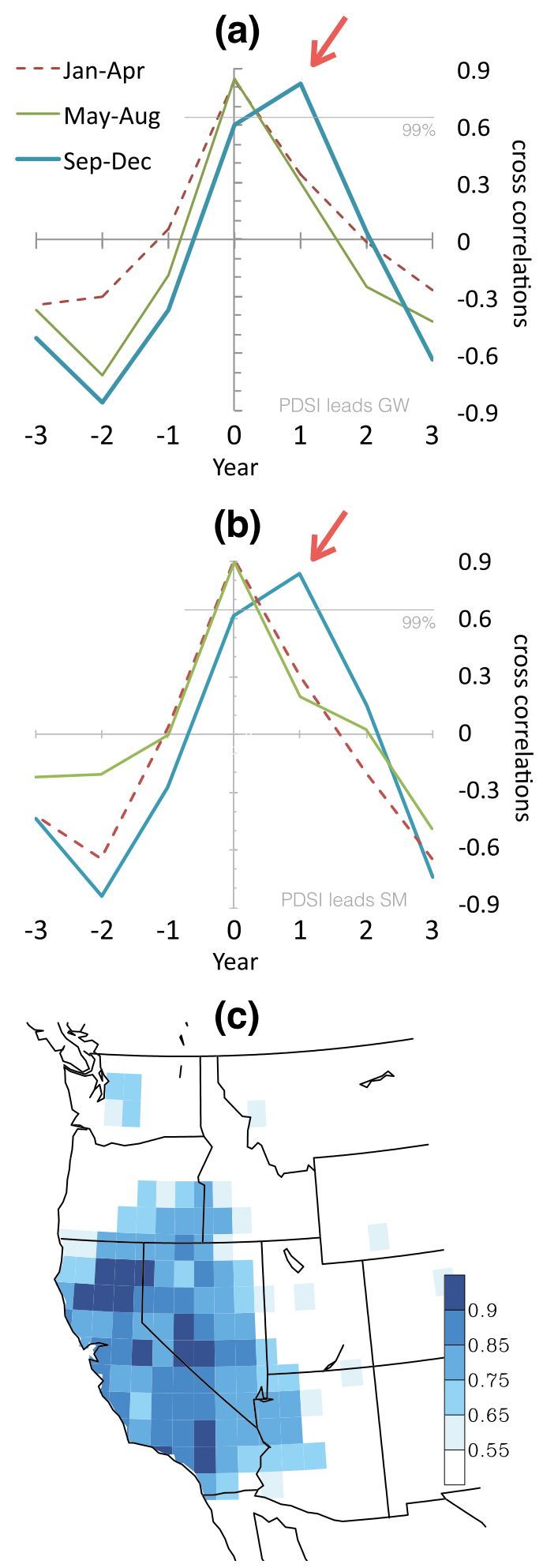

FIG. 2. (a) Cross correlations between PDSI and LWET over the Central Valley for each 4-month season as indicated in the legend. The gray line indicates the $99 \%$ confidence level; the red arrow indicates the significant lagged correlation in the SeptemberDecember season. (b) As in (a), but for soil moisture and LWET. (c) Point-to-point correlations between the September-December PDSI and LWET in the following year. Only values that are above the $99 \%$ confidence level are plotted.
Central Valley during 2002-14. As shown in Fig. 2a, the September-December period is the only season whose correlations are significant both at the current year (year 0 ) and at a 1-yr lag (year +1 ), suggesting a prolonging effect of meteorological drought on groundwater. It could mean that groundwater decline in autumn is maintained over a 2-yr period that persists approximately one full year after drought has occurred (or seized). A similar pattern in the correlations is observed between soil moisture and LWET (Fig. 2b) as well as precipitation (not shown), which lends support to the prolonging effect of drought on groundwater depletion. We also computed the point-to-point correlation between the grid-scale PDSI (year 0) and LWET (year +1) to delineate the geographical distribution of this year +1 correlation, using the September-December data. As shown in Fig. 2c, significant correlations encompass the Central Valley and extend into Nevada, southeastern Oregon, and northwestern Arizona. This regional extent of year +1 correlations suggests that the occurrence of drought affecting the Central Valley is associated with a largerscale climate pattern beyond the state of California.

Of further relevance, prior to the twenty-first century the 1-yr lag in the drought-groundwater correlation was not apparent: Fig. 3a presents evidence from wells in the Central Valley by computing correlations for a series of sliding, trailing 15-yr windows between PDSI (year 0) and groundwater level (year +1$)$, based on SeptemberDecember (hereafter "sliding correlations"). Actual time series of PDSI and groundwater level are displayed in Fig. 4a for visual inspection. The contemporaneous (year 0 ) correlations are rather stable and remain marginally significant throughout the analysis period, as expected. By comparison, the lagged (year +1$)$ correlations increase drastically and become significant $(p<$ $0.01)$ at the beginning of the twenty-first century. Prior to that, the year +1 correlations are insignificant, suggesting that the situation of protracted groundwater decline a full year after drought was not the case. A similar analysis using soil moisture (Fig. 3b) obtained the same conclusion, that the year +1 correlations have increased prominently since 2005 . This strengthened effect of drought in prolonging groundwater depletion was previously undocumented. The cause of such a change in lagged correlations is manifold and we acknowledge that a lot of factors that are involved in water management could obscure the relationship between drought and groundwater; these are addressed in section 4.

We tested the significance for the difference in the sliding correlations by applying a bootstrapping scheme with 500 pairs of correlated white noise time series, following Gershunov et al. (2001); the test result 

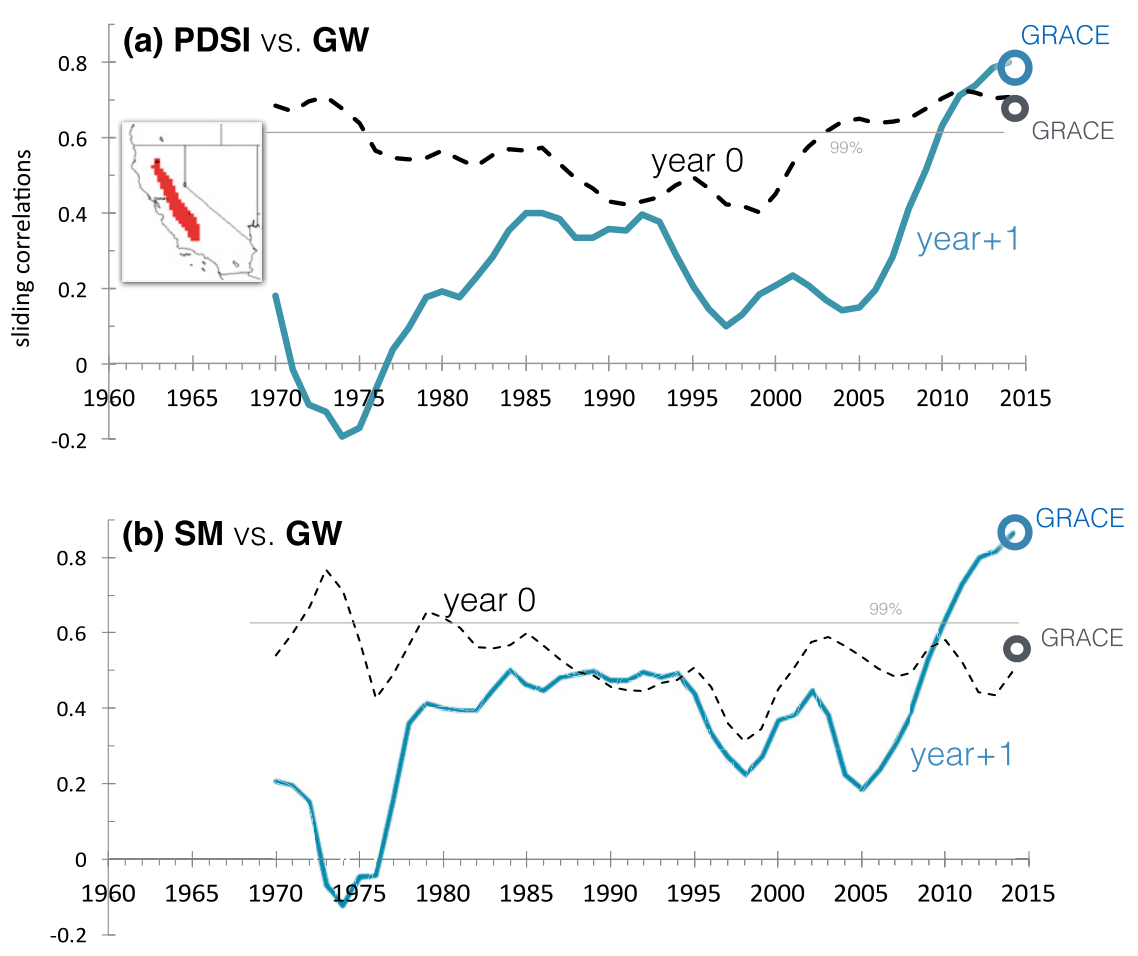

(c) PDSI vs. SM, P \& T

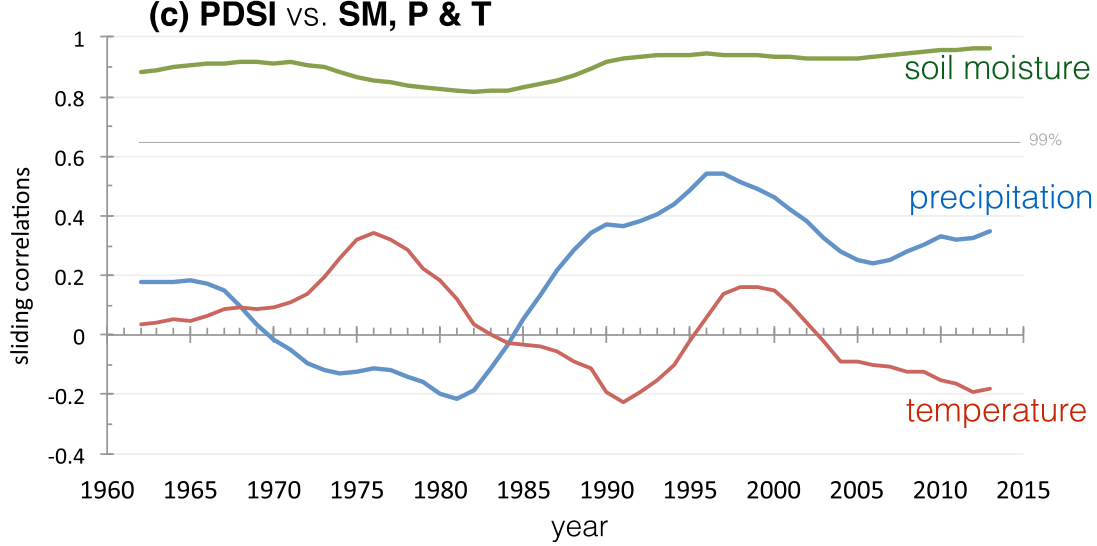

FIG. 3. (a) Sliding correlations between the Central Valley PDSI and the groundwater level $(\mathrm{GW})$ in the following year (year +1 ; blue solid line) and in the same year (year 0; black dashed line), computed with a 15-yr running window (one sided). The LWET correlations with PDSI are indicated by thick circles for 2002-14. Gray horizontal lines indicate the $99 \%$ confidence level. (b) As in (a), but for soil moisture (SM) and GW. (c) Sliding correlations (no lag) between the PDSI and SM (green line), precipitation $P$ (blue line), and surface air temperature $T$ (red line) within the Central Valley using a centered, 15-yr running window.

indicates a significant post-2005 difference at $p<0.01$. We also examined the sliding correlations using various window sizes from 10 to 20 years, and those too yielded consistent results (not shown). In terms of geographical difference, we computed these correlations from each subregion of the Central Valley as indicated in the supplemental material. The result as shown in Fig. S1 suggests that the correlations are not sensitive to the region we selected (though the southern Central Valley exhibits a lower year +1 correlation in recent years). Moreover, the LWET-PDSI correlations for the 2002-14 period (indicated by open circles in Fig. 3a) align with the well data analysis, and this agreement suggests that any potential bias that resulted from the signal leakage effect of GRACE within the Central Valley is minimal.

Since groundwater depletion in semiarid areas such as the Central Valley is largely controlled by soil moisture storage change (Rodell et al. 2007; Long et al. 2013), the 


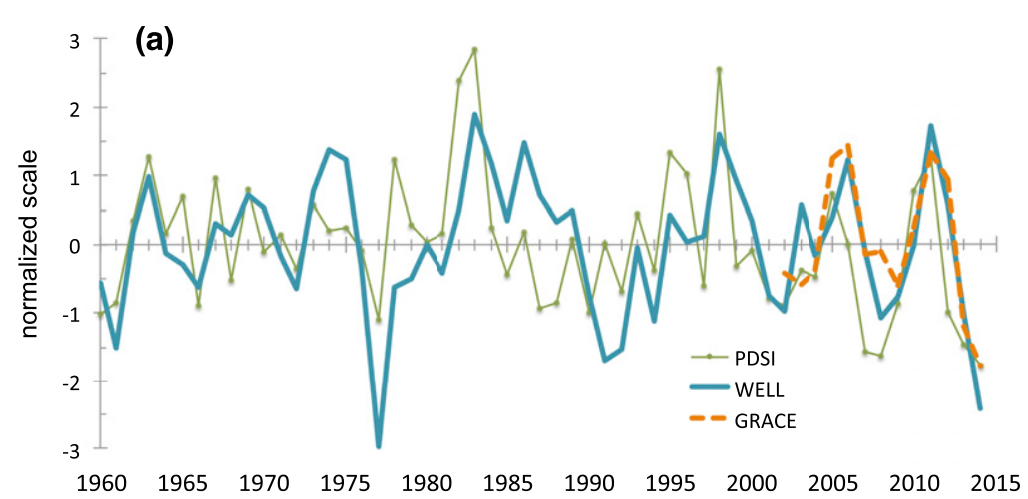

(b) PDSI wavelet spectrum

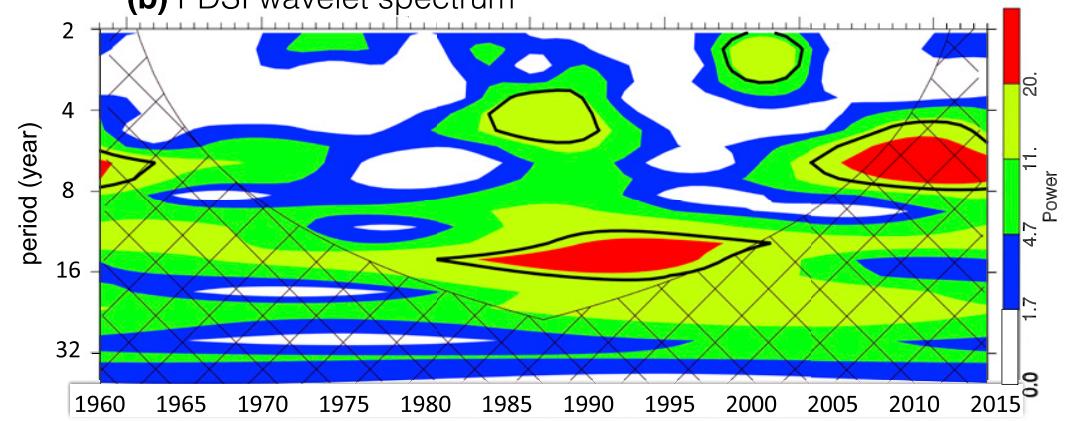

(c) PDSI-groundwater wavelet coherency and phase

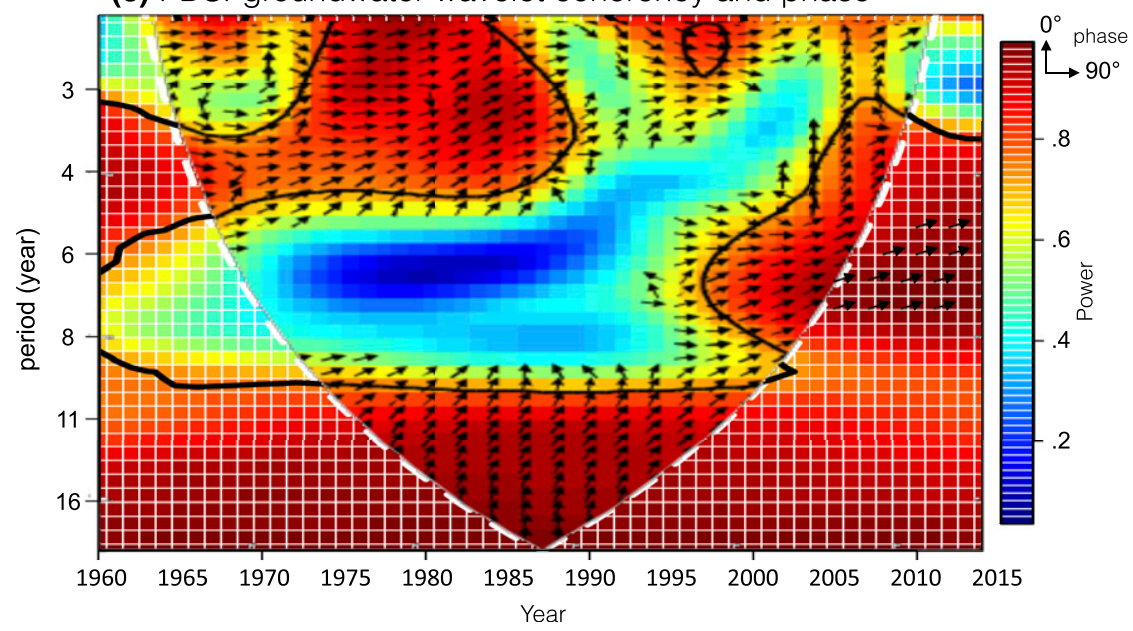

FIG. 4. (a) Time series of the September-December PDSI (green line), LWET (orange dashed line), and GW (blue line) from 1960 to 2014. (b) Wavelet spectrum of the PDSI using the Morlet parameter- 6 approach, in which the contour levels are chosen so that $75 \%, 50 \%$, $25 \%$, and $5 \%$ of the wavelet power are above each level. (c) Wavelet coherency (shading) and phase (vectors) between the PDSI and GW. Vectors pointing to the right indicate a quarter phase. The cone of influence and the $95 \%$ confidence level based on red noise are hatched/ contoured.

expectation is that groundwater storage, soil moisture, and drought occurrence would be highly correlated (Famiglietti et al. 2011; Castle et al. 2014). Figure 3c reflects such a process through the computation of sliding correlations between PDSI and soil moisture, precipitation, and surface air temperature within the
Central Valley. The PDSI shows a weak association with precipitation and temperature, although the correlations with precipitation have increased after 1980 (yet insignificant). The PDSI's correlation with soil moisture has been significant and consistently high $(\sim 0.9)$ throughout the past 65 years. Therefore, it is possible 
that the prolonging effect of drought and low soil moisture on groundwater level has increased. This notion echoes recent observations (AghaKouchak et al. 2014a; Griffin and Anchukaitis 2014; Diffenbaugh et al. 2015) that long-term warming during the recent decades and the record high temperature in summer can aggravate drought severity through increased evapotranspiration (Anderson et al. 2015), which furthers the reduction in soil moisture. Enhanced high pressure anomaly over the West Coast that was linked to increased anthropogenic warming (Wang et al. 2014; Diffenbaugh et al. 2015) also contributes to the lengthening of dry/warm days, which helps increase evaporation from the soils.

To illustrate the history of drought variability experienced in the Central Valley, Fig. 4a shows the September-December PDSI alongside the groundwater well levels and LWET. The low-frequency variability in all these datasets is discernable. It appears that the tendency for any drought to last longer than 2 years has become more pronounced. The changing drought frequency was assessed using the wavelet spectral analysis (Torrence and Compo 1998) of the PDSI, and the result is shown in Fig. 4b. Since the late 1990s, spectral power within the 4-6-yr frequency undergoes considerable amplification. The effect of this amplified drought variation on groundwater was examined by computing the wavelet spectral coherency between PDSI and groundwater level using the formulation derived by Grinsted et al. (2004). As shown in Fig. 4c, significant coherency between the two variables in the 4-6-yr frequency appears after 1995 with a phase difference of (vector pointing toward) $75^{\circ}$; this phase difference amounts to a time lag of 1 year within a 4-6-yr "cycle," lending support to the increased year +1 correlations presented in Fig. 3a.

Noteworthy is the 1980-95 period when the Central Valley experienced a lower-frequency climate fluctuation in the 10-16-yr time scale (Fig. 4b) in which the depletion of groundwater lags drought by certain years (Fig. 4a). Previous research has reported an energetic 10-20-yr (or quasi decadal) oscillation in the western United States, and its signal is especially pronounced in Northern California (Wang et al. 2009; St. George and Ault 2011). As is shown in Fig. $4 \mathrm{c}$, the $50^{\circ}$ phase difference within the significant 10-16-yr coherency indicates a time lag of about 2-3 years. Consequently, the prolonging effect of drought on groundwater depletion during this time period is not revealed as strongly from the year +1 correlations in Fig. 3a.

\section{Discussion}

What are the possible causes for the recent increase in the lagged correlations between the PDSI and groundwater level in the Central Valley? In terms of climatic factors, there is a tendency that drought conditions in California have become increasingly more intense and lasted longer (Cayan et al. 2010; MacDonald 2010; Diffenbaugh et al. 2015). Previous studies (Wang et al. 2009; Cayan et al. 2010; Seager and Vecchi 2010) have noted an intensification in the low-frequency drought variation across the western United States, echoing the result shown in Fig. 4. Recent studies (Wang et al. 2015; Yoon et al. 2015b) linked this intensified drought variation with strong ENSO events that modulate California's climate not only through the warm and cold phases but also their precursor patterns. Using large-member ensemble simulations, Yoon et al. (2015a) found a large increase specifically in the 4-6-yr spectral coherency shared by the El Niño-La Niña cycle and California's precipitation, vegetation index, and fire probability and attributed such a change to an increased association with the El Niño-La Niña teleconnections. To put these results into the context of this study, we adopted from Yoon et al. (2015a) the power spectrum of California's winter precipitation simulated by the Community Earth System Model, version 1 (CESM1), Large Ensemble Community Project, which is displayed in Fig. S2a. The result indicates a prominent increase in the variation of the 4-6-yr frequency. Likewise, Fig. S2b shows the spectral coherency of the precipitation with the ENSO cycle (represented by the Niño-3.4 index), and it too suggests a strengthened relationship in the same 4-6-yr frequency. This additional result is supportive of the 4-6-yr wavelet coherency between the PDSI and groundwater in the Central Valley observed in Fig. 4c, as well as their phase lag of 1 year.

In terms of local effects, the 2014 drought induced heat waves that resulted in the first half of the year being the hottest in 120 years of state record (James 2014); this subsequently exacerbated the drought situation and, according to the observations by Bertoldi et al. (1991) and Anderson et al. (2015), would prompt further withdrawal from the aquifer. Changes to surface water deliveries could very well affect the correlations discussed, yet there have been indications that they are not the leading cause for the increase in year +1 correlations. For instance, by focusing on the Colorado River basin, Famiglietti (2014) noted a disconnect between reservoir storage and groundwater level while stating that "the steepest rate of groundwater storage decline (in the upper Basin in 2013) follows exceptional drought conditions in 2012 and record low Rocky Mountain snowpack." While it is expected that low snowpack affects surface water availability and thus tends to promote groundwater pumping, the notion in Famiglietti (2014) (alongside his Fig. 3) suggests that drought is the 
leading contributor to groundwater behavior, rather than changes in reservoir storage. If this idea is applied to California, it would imply that drought is the leading cause for the change in year +1 correlations since the 2000s rather than the change in reservoir storage. Meanwhile, it is also possible that existing water management practices in surface water resources, nonlocal water supplies, river flow control, reclamation, changes in usage, etc. could complicate the relationship between drought and groundwater level. Given that groundwater is unregulated and has been mined indiscriminately during this prolonged drought, some of the findings as presented here may be tempered.

In the context of climate change, since the CESM1 simulation of the changing association between ENSO cycle and California's precipitation as shown in Fig. S2 was derived from a higher representative concentration pathway (RCP8.5) of anthropogenic greenhouse gases, the amplification in the drought variation and the associated protraction of groundwater depletion is likely to continue. Further research is necessary to comprehensively understand the climate and hydrological linkages that manifest in the groundwater response to the changing frequencies of drought.

\section{Conclusions}

We present evidence that, since the beginning of the twenty-first century, groundwater levels in the Central Valley have tended to decline not only in response to drought conditions of the same year but also in the following year. In addition to the climatic factors outlined earlier, the reported long-term increase in groundwater withdrawal could play a role. Undeniably, the accelerated depletion in groundwater is linked to increased withdrawal (Famiglietti et al. 2011; Scanlon et al. 2012; Famiglietti 2014) and the drilling boom since 2014 is yet another compelling piece of evidence. However, quantifying the role of human withdrawal of groundwater is difficult because of the lack of reliable data. Performing land surface modeling with irrigation fluxes by utilizing GRACE groundwater storage estimate, as was recently done by Anderson et al. (2015), may offer a clue. Nonetheless, the present analysis for the Central Valley points to the fact that the effects of drought are becoming overarching and can be enduring. Despite changing water use habits, the water table continues to drop while drought becomes longer and more severe.

As of January 2016, an El Niño has fully developed and an alert was announced by the NOAA CPC (http:// www.cpc.ncep.noaa.gov/products/analysis_monitoring/ enso_advisory/). This El Niño, if it persists through spring 2016 (as it is being predicted to), could enhance precipitation in California and bring some relief to the current drought conditions. However, the analysis presented here suggests that, even in the face of some drought recovery, groundwater depletion in the Central Valley will likely continue into late 2016, resulting in further reduction in groundwater level. The groundwater table in the Central Valley has been declining to such a degree that it requires a deeper understanding of the temporal dynamics of drought, their dependence on regional climate variability and change, and their implications for water demand and use in all forms.

Acknowledgments. Insightful comments offered by Dr. Andy Wood and two anonymous reviewers, as well as discussions with Matt Rodell, Hiroko Kato, and Calvin Poulsen, are highly appreciated. We are grateful to Laurel Rogers and Patricia Orlando of USGS for providing crucial water information. Data of GRACE Tellus is supported by NASA's Making Earth System Data Records for Use in Research Environments (MEaSUREs) program available at http://grace.jpl. nasa.gov. CESM1 Large Ensemble Project (LEP) data are available at https://www2.cesm.ucar.edu/models/ experiments/LENS. This research was supported by the Bureau of Reclamation Grant R13AC80039, NASA Grant NNX13AC37G, and the Utah Agricultural Experiment Station, Utah State University.

\section{REFERENCES}

AghaKouchak, A., L. Cheng, O. Mazdiyasni, and A. Farahmand, 2014a: Global warming and changes in risk of concurrent climate extremes: Insights from the 2014 California drought. Geophys. Res. Lett., 41, 8847-8852, doi:10.1002/ 2014GL062308.

- D. Feldman, M. J. Stewardson, J.-D. Saphores, S. Grant, and B. Sanders, 2014b: Australia's drought: Lessons for California. Science, 343, 1430-1431, doi:10.1126/science.343.6178.1430.

Anderson, R. G., M. H. Lo, S. Swenson, J. S. Famiglietti, Q. Tang, T. H. Skaggs, Y. H. Lin, and R. J. Wu, 2015: Using satellitebased estimates of evapotranspiration and groundwater changes to determine anthropogenic water fluxes in land surface models. Geosci. Model Dev., 8, 3021-3031, doi:10.5194/ gmd-8-3021-2015.

Bertoldi, G. L., R. H. Johnston, and L. D. Evenson, 1991: Ground water in the Central Valley, California-A summary report. USGS Professional Paper 1401-A, 44 pp. [Available online at http://pubs.usgs.gov/pp/1401a/report.pdf.]

Castle, S. L., B. F. Thomas, J. T. Reager, M. Rodell, S. C. Swenson, and J. S. Famiglietti, 2014: Groundwater depletion during drought threatens future water security of the Colorado River basin. Geophys. Res. Lett., 41, 5904-5911, doi:10.1002/2014GL061055.

Cayan, D. R., T. Das, D. W. Pierce, T. P. Barnett, M. Tyree, and A. Gershunov, 2010: Future dryness in the Southwest US and the hydrology of the early 21st century drought. Proc. Natl. Acad. Sci. USA, 107, 21 271-21 276, doi:10.1073/pnas.0912391107. 
Dai, A., 2013: Increasing drought under global warming in observations and models. Nat. Climate Change, 3, 52-58, doi:10.1038/ nclimate1633.

Diffenbaugh, N. S., D. L. Swain, and D. Touma, 2015: Anthropogenic warming has increased drought risk in California. Proc. Natl. Acad. Sci. USA, 112, 3931-3936, doi:10.1073/pnas.1422385112.

Famiglietti, J. S., 2014: The global groundwater crisis. Nat. Climate Change, 4, 945-948, doi:10.1038/nclimate2425.

—_, and Coauthors, 2011: Satellites measure recent rates of groundwater depletion in California's Central Valley. Geophys. Res. Lett., 38, L03403, doi:10.1029/2010GL046442.

Faunt, C. C., 2009: Groundwater availability of the Central Valley aquifer, California. USGS Professional Paper 1766, 225 pp. [Available online at http://pubs.usgs.gov/pp/1766/PP_1766.pdf.]

Gershunov, A., N. Schneider, and T. Barnett, 2001: Low-frequency modulation of the ENSO-Indian monsoon rainfall relationship: Signal or noise? J. Climate, 14, 2486-2492, doi:10.1175/ 1520-0442(2001)014<2486:LFMOTE > 2.0.CO;2.

Griffin, D., and K. J. Anchukaitis, 2014: How unusual is the 20122014 California drought? Geophys. Res. Lett., 41, 9017-9023, doi:10.1002/2014GL062433.

Grinsted, A., J. C. Moore, and S. Jevrejeva, 2004: Application of the cross wavelet transform and wavelet coherence to geophysical time series. Nonlinear Processes Geophys., 11, 561566, doi:10.5194/npg-11-561-2004.

Howard, B. C., 2014: California drought spurs groundwater drilling boom in Central Valley. National Geographic, 16 August. [Available online at http://news.nationalgeographic.com/ news/2014/08/140815-central-valley-california-drilling-boomgroundwater-drought-wells/.]

Howitt, R., J. Medellín-Azuara, D. MacEwan, J. Lund, and D. Sumner, 2014: Economic analysis of the 2014 drought for California agriculture. Center for Watershed Sciences, University of California, Davis, $20 \mathrm{pp}$. [Available online at https:// watershed.ucdavis.edu/files/content/news/Economic_Impact_ of_the_2014_California_Water_Drought.pdf.]

James, I., 2014: In California, record heat adding to extreme drought. USA Today, 11 August. [Available online at http:// www.usatoday.com/story/news/nation/2014/08/11/record-heatextreme-drought-california/13904797/.]

Kennedy, C., 2014: Groundwater: California's big unknown. NOAA, accessed 2 February 2016. [Available online at https:// www.climate.gov/news-features/event-tracker/groundwatercalifornia \% E2\%80\%99s-big-unknown.]

Landerer, F., and S. Swenson, 2012: Accuracy of scaled GRACE terrestrial water storage estimates. Water Resour. Res., 48 W04531, doi:10.1029/2011WR011453.

Long, D., B. R. Scanlon, L. Longuevergne, A. Y. Sun, D. N. Fernando, and H. Save, 2013: GRACE satellite monitoring of large depletion in water storage in response to the 2011 drought in Texas. Geophys. Res. Lett., 40, 3395-3401, doi:10.1002/grl.50655.

MacDonald, G. M., 2010: Water, climate change, and sustainability in the Southwest. Proc. Natl. Acad. Sci. USA, 107, 21 256-21 262, doi:10.1073/pnas.0909651107.

Rodell, M., J. Chen, H. Kato, J. S. Famiglietti, J. Nigro, and C. R. Wilson, 2007: Estimating groundwater storage changes in the Mississippi River basin (USA) using GRACE. Hydrogeol. J., 15, 159-166, doi:10.1007/s10040-006-0103-7.

Scanlon, B., L. Longuevergne, and D. Long, 2012: Ground referencing GRACE satellite estimates of groundwater storage changes in the California Central Valley, USA. Water Resour. Res., 48, W04520, doi:10.1029/2011WR011312.

Seager, R., and G. A. Vecchi, 2010: Greenhouse warming and the 21st century hydroclimate of southwestern North America. Proc. Natl. Acad. Sci. USA, 107, 21 277-21 282, doi:10.1073/ pnas.0910856107.

St. George, S., and T. R. Ault, 2011: Is energetic decadal variability a stable feature of the central Pacific Coast's winter climate? J. Geophys. Res., 116, D12102, doi:10.1029/ 2010JD015325.

Torrence, C., and G. P. Compo, 1998: A practical guide to wavelet analysis. Bull. Amer. Meteor. Soc., 79, 61-78, doi:10.1175/ 1520-0477(1998)079<0061:APGTWA >2.0.CO;2.

Wang, S.-Y., R. R. Gillies, J. Jin, and L. E. Hipps, 2009: Recent rainfall cycle in the Intermountain Region as a quadrature amplitude modulation from the Pacific decadal oscillation. Geophys. Res. Lett., 36, L02705, doi:10.1029/2008GL036329.

—, L. Hipps, R. R. Gillies, and J.-H. Yoon, 2014: Probable causes of the abnormal ridge accompanying the 2013-2014 California drought: ENSO precursor and anthropogenic warming footprint. Geophys. Res. Lett., 41, 3220-3226, doi:10.1002/ 2014GL059748.

—, W.-R. Huang, and J.-H. Yoon, 2015: The North American winter 'dipole' and extremes activity: A CMIP5 assessment. Atmos. Sci. Lett., 16, 338-345, doi:10.1002/asl2.565.

Westerling, A. L., H. G. Hidalgo, D. R. Cayan, and T. W. Swetnam, 2006: Warming and earlier spring increase western U.S. forest wildfire activity. Science, 313, 940-943, doi:10.1126/ science.1128834

Yoon, J. H., S.-Y. Wang, R. R. Gillies, L. Hipps, B. Kravitz, and P. J. Rasch, 2015a: Extreme fire season in California: A glimpse into the future? Bull. Amer. Meteor. Soc., 96, S5-S9, doi:10.1175/BAMS-EEE_2014_ch2.1.

, B. Kravitz, L. E. Hipps, and P. J. Rasch, 2015b: Increasing water cycle extremes in California and in relation to ENSO cycle under global warming. Nat. Commun., 6, 8657, doi:10.1038/ncomms9657. 